\title{
BİST SINAİ İŞLETMELERİNİN GRİ ENTROPİ-EATWIOS BÜTÜNLEŞİK YAKLAŞIMI İLE PERFORMANS DEĞERLENDİRMESİ
}

\author{
Aşkın ÖZDAĞoĞLU*
}

öz

Sanayi alanında yapılan yatııımlar bir ülkenin itici gücüdür. Yoğun rekabet ortamı dikkate alındığında, sanayi işletmelerinin performanslarının takip edilmesi önemli bir husustur. Buna yönelik olarak, işletmeler kısıtlı kaynaklarını etkin bir şekilde kullanarak daha fazla çıktı elde etmeye çalışmaktadırlar. Ancak sanayi işletmelerinin performansını değerlendirirken göz önüne alınması gereken bir çok girdi ve çıktı unsuru bulunmaktadır. Bu farkı girdi ve çıktı unsurlarını bir arada düşünerek performansı incelemek kolay olmamaktadır. EATWIOS farklı girdi ve çıkı unsurlarını birlikte inceleyerek performans değerlendirmeye imkan sağlayan yöntemlerden birisidir. Bu noktadan hareketle, bu çalışmanın amacl, gri entropi yönteminden elde edilen ağırıkları kullanarak EATWIOS yöntemi ile BİST Sınai kategorisinde yer alan 152 işletmenin performanslarının incelenmesidir.

Anahtar Sözcükler: BISST SInai, Gri Entropi, EATWIOS

\section{EVALUATION OF BIST INDUSTRY COMPANIES WITH GRAY ENTROPY-EATWIOS INTEGRATED APPROACH}

\section{ABSTRACT}

Investments in the industrial areas are the driving forces of a country. Considering the intense competition environment, monitoring the performances of industrial enterprises is an important issue. For this purpose, businesses are actively seeking more output using limited resources. However, there are many input and output elements that should be considered when evaluating the performance of industrial enterprises. It is not easy to examine performance by considering these different input and output elements. EATWIOS is one of the ways to evaluate performance by examining different input and output elements together. From this point of view, the purpose of this study is to analyze the performances of 152 companies in BIST Industry index with EATWIOS method by using gray entropic weights.

Keywords: BIST Industry, Gray Entropy, EATWIOS

* Dokuz Eylül Üniversitesii, İşletme Fakültesi, İşletme Bölümü, İzmir, E-posta: askin.ozdagoglu@deu.edu.tr 


\section{BİST Sinai İşletmelerinin Gri Entropi-EATWIOS Bütünleşik Yaklaşımı ile Performans Değerlendirmesi}

\section{GİRİş}

Sanayi işletmeleri bir ülkenin gelişiminin itici gücüdür. Daha fazla katma değer yaratarak ortaya fiziksel bir ürün koymak bir ülkenin gayri safi milli hasılası için çok önemli bir unsurdur. Ülkelerin rekabet endeksi açısından iyi bir konuma yükselebilmesi de sanayiye yapılan yatırımlara bağlıdır. Bu nedenle sanayi işletmelerinin performansının analiz edilmesi o ülkedeki gelişimin takip edilmesi açısından hayati bir öneme sahiptir. Ancak sanayi işletmelerinin performansını değerlendirirken gözönüne alınması gereken birçok girdi ve çıktı unsuru bulunmaktadır. Bu farklı girdi ve çıkı unsurlarını bir arada düşünerek performansı incelemek ciddi bir sorun olarak karşımıza çıkmaktadır. Bu değerlendirmeleri yapabilmek amacıyla çeşitli çok ölçütlü karar verme yöntemleri geliştirilmiştir. Bu çok ölçütlü karar verme yöntemlerinin her birisinin kendine özgü avantajları ve deavantajları bulunmaktadır. Efficiency Analysis Technique with Input Output Satisficing (EATWIOS) farklı girdi ve çıkı unsurlarını birlikte inceleyerek performans değerlendirmeye imkan sağlayan bir çok ölçütlü karar verme yöntemi olarak karşımıza çıkmaktadır. Adı geçen yöntemin diğer bir özelliği de literatürde diğer çok ölçütlü karar verme yöntemlerine göre daha yeni olması ve literatürde henüz yaygınlaşmamsıdır. Bu düşünceden hareketle, bu çalışmada EATWIOS yöntemi tercih edilmiştir. EATWIOS yönteminin, performans göstergelerinin ağırlıklarını belirlemede kullanılamaması da yöntemin dezavantajını oluşturmaktadır. Bu dezavantajı giderebilmek amacıyla, ilk olarak gri entropi yöntemi ile performans göstergelerinin ağırlıkları bulunmuştur. Ardından EATWIOS yöntemi ile gri entropiden elde edilen ağırlıklar bütünleştirilerek performans değerleri bulunmuş ve sıralanmıştır.

Çalışmanın düzeni şu şekildedir. Öncelikle, bu çalışma kapsamında kullanılan gri entropi ve EATWIOS yöntemleri ile ilgili literatür incelemesi yapılmıştır. Literatür incelemesinin ardından sırasıyla gri entropi ve EATWIOS yöntemlerinin işleyişi matematiksel ifadeler ile açıklanmıştır. Daha sonra uygulama kısmına geçilmiş ve BİST Sınai kategorisinde yer alan 152 firmanın girdi ve çıktı unsurları veri seti olarak toplanarak hesaplamalar gerçekleştirilmiştir. Uygulama kısmından sonra sonuç bölümünde genel değerlendirmeler yapılmıştır. 


\section{Aşkın ÖZDAĞoĞLU}

\section{LITTERATÜR İNCELEMESİ}

Literatürde gri entropi konusu araştıııldığında pek çok farklı alanda uygulama amaçı kullanıldığı görülmektedir. Daha iyi görüntü modellemesi amacıyla gri entropiye dayalı bir model kurulmuştur ( $\mathrm{Li}$, Tong ve Xiao, 2011). Asfaltın kimyasal yapısının değişimini incelemek amacıyla gri entropi teorisinde dayalı bir analiz yapılmıştı (Wang, Sun ve Qin, 2015). Asfalt karışımının özelliklerini incelemek amacıyla gri entropiye dayalı bir korelasyon analizi yapılmıştır (Wang, Wang ve Ai, 2014). Benzer şekilde asfalt karışımının yüksek sıcaklıklardaki performansını değerlendirmede gri ilişkisel entropi kullanılmıştır (Gao, Wang, You ve Yang, 2018). Beş büyük Japon şehrindeki sülfür dioksit, karbon monoksit gibi hava kirliliği değerlerini hesaplamak amacıyla gri entropi ve gri ilişkisel analiz yöntemlerinden yararlanılmıştır (You, Shu, Chen ve Shyu, 2017). Malzeme performanslarını tahminlemek amacıyla gri entropi ve regresyon modelleri birlikte kullanımıştır (Sivasankar ve Jeyapaul, 2012). Bilgisayar görüntülerine dayanarak taze ve dondurulmuş et ürünlerinin doğru bir şekilde sınıflandırıması için gri birliktelik matrisleri oluşturulmuş ve bu matrislerin oluşturulmasında gri entropiden de yararlanılmıştır ( $\mathrm{Ma}, \mathrm{Pu}$, Sun, Gao, Qu ve Ma, 2015). Et ürünlerine yönelik kurulan modelinin balık ürünleri için de kullanıldığı görülmüştür (Cheng ve Sun, 2015). Manganez oksit içeren cihazların incelenmesinde parametreleri seçerken gri entropiden yararlanılmıştır (Chen, Kao, Huang, Li, Cheng, Wu ve Wu, 2017). Görüntü filtreleme amacı ile tavlama benzetimi algoritması gri entropi yöntemi ile çözülmüştür (Fei, Jinfei, Zhisheng, Ruwen ve Songqing, 2014). Kalıp enjeksiyon parametrelerinin optimizasyonunda gri entropiden yararlanılmışır (Bhattacharyaa ve Bepari, 2014). Bilgisayar üzerinden öğrenmenin performansını değerlendirmek amacıyla gri ilişkisel entropiden de yararlanılmıştır (Chou ve Tsai, 2009). Radar görüntülerinin daha sağlıklı bir biçimde yorumlanması için çeşitli algoritmalar denenmiş ara aşamalarda gri entropi kapsamında gri sayılar kullanıımışı ( $\mathrm{Ma}$, Liang, Guo, Fan ve Yin, 2011). Radar görüntülerine ilişkin benzer bir çalışmada da iki boyutlu gri entropi modeli kurulmuştur (Hanbay ve Talu, 2014). Burada belirtilen çalışmalardan da görüldüğü üzere gri entropi yöntemi metalurji, gıda, optik gibi pek çok bilim alanında kullanılmışıı. İşletme kararlarına yönelik kullanıldığı çalışmalar da izleyen paragrafta toplanmıştır.

Gri entropi yöntemi; birçok ölçütlü karar verme probleminde ölçüt ağırlıklarını belirleme teknikleri arasında gösterilmiştir (Jha, Kumar,

Kumari ve Bepari, 2014). E-pazarlama faaliyetlerinin otel performansı 


\section{BİST Sinai İşletmelerinin Gri Entropi-EATWIOS Bütünleşik Yaklaşımı ile Performans Değerlendirmesi}

üzerindeki etkisini araştırmak üzere gri entropi ve veri zarflama analizi yöntemleri birlikte kullanılmıştır (Shuai ve Wu, 2011). Yeşil uygulamalar kapsamında yeni ürün geliştirme sürecinde etkili olan kriterlerin ağırlıklarının belirlenmesinde analitik ağ süreci ve gri entropi yöntemleri kullanılmıştır (Tseng ve Chiu, 2012). Yeşil tedarikçilerin seçimi ve değerlendirilmesi kapsamında yapılan literatür taramasına dayalı bir inceleme makalesinde gri entropi yöntemi de kullanılan yöntemlerden biri olarak ifade edilmiştir (Govindan, Rajendran, Sarkis ve Murugesan, 2015). Bu çalışmalar doğrultusunda, gri entropi yönteminin işletmecilik alanında da kullanıldığı görülmektedir. İzleyen paragrafta EATWIOS yöntemi ile ilgili çalışmalar hakkında bilgi verilecektir.

Bireysel emeklilik ürünleri satan firmaların performansları çıktı tatmin seviyeleri belirlenerek değerlendirilmiştir (Özbek, 2015a). Türk Kızılay teşkilatının 2012,2013 ve 2014 yıllarına ilişkin performansı veri zarflama analizi, OCRA ve çוktı tatmin seviyelerini esas alan EATWIOS yöntemleri ile incelenmiştir (Özbek, 2015b). Altın madeni şirketlerinin performansı finansal tablolar aracılığı ile değerlendirilmiştir (Özbek, 2016). Hindistan futbol ligindeki oyuncuların performansları çıktı tatmin seviyelerini dikkate alarak karşılaştııımıştır (Kumar, Singh, Verma ve Sonal, 2016). Şirket sosyal sorumluluğu bakış açısından etkinlik analizi yapılırken girdi ve çıktılar için tatmin seviyelerinin belirlenmesinin avantajları ve dezavantajları irdelenmiştir (Peters ve Zelewski, 2016). Tedarik zincirinde yer alan tedarikçilerin performanslarını değerlendirmek üzere girdi tatmin seviyelerini dikkate almayacak şekilde yöntemden yararlanılmıştır (Bansal, Sing, Issar ve Varkey, 2014). EATWIOS yöntemine ilişkin açıklamaların ardından Gri entropi yönteminin işleyişi izleyen bölümde matematiksel olarak açıklanmıştır.

\section{Gri Entropi}

Gri entropi bir karar verme problemindeki ölçüt ağırlıklarını tespit edebilmek için kullanılabilecek araçlardan birisidir. Gri entropi yöntemine göre ölçüt ağırlıklarının bulunma süreci sırasıyla aşağıdaki gibi gösterilebilir (Shuai ve Wu, 2011: 8766; You vd., 2017: 3884-3886). Ölçüt ağırlıklarının bulunmasında ilk adım normalizasyon işleminin uygulanmasıdır. Gri entropi'ye yönelik olarak yapılan normalleştirme işlemi Eşitlik 1'de gösterilmiştir.

$$
\begin{gathered}
\text { is alternatif } ; i=1,2,3, \ldots, m \\
j \text { : ölçüt, unsur veya faktö } r ; j=1,2,3, \ldots, n
\end{gathered}
$$




\section{Aşkın ÖZDAĞoĞLU}

$$
\begin{aligned}
& x_{i j} ; j \text {. ollçüt açısindan } i \text { alternatifin değeri } \\
& z_{i j} ; j \text {. ollçüt açısından } i \text {. alternatifin normalleştirilmiş değeri } \\
& z_{i j}=\frac{x_{i j}}{\sum_{i=1}^{M I} x_{i j}}
\end{aligned}
$$

Normalleştirilmiş değerlerden yararlanarak gri entropi değerini elde etmek için öncelikle $W_{e}\left(z_{i j}\right)$ değerlerinin bulunması gerekmektedir. $W_{e}\left(z_{i j}\right)$ değerlerinin hesaplanması Eşitlik 2'de verilmiştir.

$$
W_{e}\left(z_{i j}\right)=z_{i j} e^{\left[1-z_{i j}\right)}+\left(1-z_{i j}\right) e^{z_{i j}}-1
$$

Normalleştirilmiş değerlerden yararlanarak gri entropi değerini elde etmek için gereken bir diğer değer de normalizasyon katsayısıdır. Normalizasyon katsayısının hesaplanması Eşitlik 3'te gösterilmiştir.

$$
K=\frac{1}{\left.6 e^{0.5}-1\right) n}
$$$$
\text { K: normalizasyon katsayıs }
$$

Bu değerler hesaplandıktan sonra belirli bir ölçüt için gri entropi değeri bulunabilmektedir. Gri entropi değerinin hesaplanması Eşitlik 4'te gösterilmiştir.

$$
e_{j}=K \sum_{i=1}^{m} W_{e}\left(\varepsilon_{i j}\right) j \text {. ölçütün gri entropi değeri }
$$

İzleyen adımda toplam entropi değerinin bulunması gerekmektedir. Toplam entropi değerinin hesaplanışı Eşitlik 5'te sunulmuştur.

$$
E=\sum_{j=1}^{n} e_{j}
$$$$
\text { E: toplam entropi değeri }
$$

Gri entropi yöntemine göre izleyen adımda her bir ölçüt için göreceli ağırlık değeri bulunmaktadır. Göreceli ağılık değerinin hesaplanışı Eşitlik 6'de verilmiştir.

$$
\lambda_{j}=\frac{1-\theta_{j}}{n-E} \lambda_{j} \dot{j} \text {. ölçütün göreceli ağırhk değeri }
$$

Gri entropi yöntemine göre son olarak her bir ölçütün normalize edilmiş ağırlık değeri hesaplanmaktadır. Normalize edilmiş ağırlık değerinin bulunması Eşitlik 7'de gösterilmiştir.

$$
\begin{aligned}
& \beta_{j} 3 \text {. olcçütün normalize edilmiş ağluk değeri } \\
& \beta_{j}=\frac{\lambda_{j}}{\sum_{j=1}^{n} \lambda_{j}}
\end{aligned}
$$




\section{EATWIOS Yöntemi}

Efficiency Analysis Technique with Input Output Satisficing (EATWIOS) yöntemi firmaların performansını ölçmek için kullanılan yöntemlerden birisidir. Yöntemin işleyişi aşağıda adım adım açıklanmıştır (Özbek, 2017).

EATWIOS yöntemi kapsamında ilk olarak girdi ve çıktı matrislerinin oluşturulması gerekmektedir. Girdi matrisi Eşitlik $8^{\prime}$ deki gibi oluşturulmaktadır.

$$
\begin{gathered}
\text { is firma; } i=1,2,3, \ldots, m \\
j: \text { girdi unsuru; } j=1,2,3, \ldots, n
\end{gathered}
$$

$x_{i j} ; i_{\text {. firmanm }} j$. girdi unsuru açısından sahip olduğu değer

$$
\left[\begin{array}{cccc}
x_{11} & x_{12} & \ldots & x_{1 n} \\
x_{21} & x_{22} & \ldots & x_{2 n} \\
-w & w & w & -w \\
x_{m 11} & x_{m 2} & \ldots & x_{m n}
\end{array}\right]
$$

Benzer biçimde bir de çıktı matrisinin bulunması gerekmektedir. Çıktı matrisi ise Eşitlik 9'da gösterildiği şekilde oluşur.

$$
k \text { : çikt unsuru; } k=1,2,3, \ldots, l
$$

$y_{i k}:$ i. firmantn $k$.çıtı unsuru açısından sahip olduğu değer

$$
\left[\begin{array}{cccc}
y_{11} & y_{12} & \ldots & y_{11} \\
y_{21} & y_{22} & \ldots & y_{21} \\
w & w & \ldots & w \\
y_{m 1} & y_{m 2} & \cdots & y_{m 1}
\end{array}\right]
$$

Girdi çıktı matrisleri oluşturulduktan sonra vektör normalizasyonu yöntemi ile normalizasyon işlemi gerçekleştirilmektedir. Girdi matrisi için vektör normalizasyonu işlemi Eşitlik $10^{\prime}$ da çıktı matrisi için vektör normalizasyonu işlemi ise Eşitlik 11'de verildiği gibi yapılmaktadır.

$$
\begin{aligned}
& s_{i j} \text { i. firmann j. girdi unsuru açısından normalize edilmiş değeri } \\
& s_{i j}=\frac{x_{i j}}{\sqrt{\sum_{i=1}^{m} x_{i j}^{2}}} \forall i, j \\
& r_{\mathrm{T} k}: \text { i. firmann } k \text {.çıtı unsuru açısından normalize edilmiş değeri } \\
& r_{\mathrm{I} k}=\frac{y_{\mathrm{ik}}}{\sqrt{\sum_{\mathrm{i}=1}^{M \mu} y_{i k}^{2}}} \forall i i_{*} k
\end{aligned}
$$

Bu işlemlerin yapılması sonucunda girdi ve çıktı matrisleri normalize edilmiş girdi ve çıtı matrislerine dönüştürülmüş olur. Normalize edilmiş girdi matrisi Eşitlik 12'de normalize edilmiş çıktı matrisi ise Eşitlik 13'teki gibi oluşmaktadır. 


\section{Aşkın ÖZDAĞoĞLU}

$$
\begin{aligned}
& {\left[\begin{array}{cccc}
s_{11} & s_{12} & \ldots & s_{1 n} \\
s_{21} & s_{22} & \ldots & s_{2 n} \\
\ldots & \ldots & \ldots & -w \\
s_{m 1} & s_{m 2} & \ldots & s_{m n}
\end{array}\right]} \\
& {\left[\begin{array}{cccc}
r_{11} & r_{12} & \ldots & r_{11} \\
r_{21} & r_{22} & \ldots & r_{21} \\
\ldots & \ldots & \ldots & \ldots \\
r_{m 1} & r_{m 2} & \ldots & r_{m n}
\end{array}\right]}
\end{aligned}
$$

Normalize edilmiş değerlerden yararlanarak girdi ve çıktı mesafe ölçüleri hesaplanır. Girdi mesafe ölçüsünün hesaplanması Eşitlik 14'te çıktı mesafe ölçüsünün hesaplanması ise Eşitlik 15 'te verilmiştir.

$$
\begin{aligned}
& i d_{i j} ; \text { i. firmann } j \cdot \text { girdi unsuru açısından mesafe ölçusüu } \\
& i d_{i j}=1-\left(\min _{i}\left\{s_{i j}\right\}-s_{i j}\right) \forall i, j \\
& o d_{i k} ; \text { i. firmanm } k \cdot \text { çıktı unsuru açısından mesafe ölçüsü } \\
& o d_{i k}=1-\left(\operatorname{mak}_{i}\left\{x_{i k}\right\}-r_{i k}\right) \forall i, k
\end{aligned}
$$

Ardından bu mesafe ölçülerinin ağırlık değerleri ile çarpılması gerekmektedir. Girdi unsurları için ağırlıklandııımış mesafe ölçüsü Eşitlik 16, çıktı unsurları için ağırlıklandırılmış mesafe ölçüsü ise Eşitlik 17 yardımıyla bulunmaktadır.

$$
\begin{aligned}
& w_{j}: j \cdot \text { girdi unsurunun ağrlhk değeri } \\
& w_{k}, k \text {,çıtı unsurunun ağırhk değeri } \\
& w_{j} i d_{i j} \\
& w_{k} \text { od } d_{i k}
\end{aligned}
$$

Çıktı unsurları için ağırlıklandırılmış mesafe ölçülerinin toplamının, girdi unsurları için ağırıklandırıımış mesafe ölçülerinin toplamına oranı da her bir firmanın performans değerini vermektedir. Firma performans değerleri Eşitlik 18 kullanılarak hesaplanabilir.

$$
\begin{aligned}
& P_{\mathrm{i}} \text { i. firmantn performans değeri } \\
& P_{\mathrm{i}}=\frac{\sum_{k=1}^{\mathbb{I}} W_{k} \text { od }}{\sum_{j=1}^{n} w_{i k}}
\end{aligned}
$$

En yüksek $P_{\mathrm{i}}$ değerine sahip olan firma en iyi performansa sahip olan firma anlamına gelmektedir.

\section{UYGULAMA}

Bu çalışmada, BİST Sınai kategorisinde yer alan sanayi işletmelerinin performansları EATWIOS yöntemi ile değerlendirilmiştir. Bu yönteme girdi olarak ağırlık vektörüne intiyaç duyulduğundan dolayı Gri 
Entropi yöntemi ile girdi ve çıktı faktörlerinin ağırlıkları hesaplanmıştır. Analiz kapsamında, BİST Sınai kategorisinde yer alan 152 sanayi işletmesinin tüm verileri Finnet veri tabanından indirilmiş ve analize tabi olan kriterlere ilişkin unsurların değerleri düzenlenmiştir.

Tablo 1: Girdi Değerleri

\begin{tabular}{|c|c|c|c|c|}
\hline & $\begin{array}{c}\text { Girdi Faktörü } 1 \\
\text { Stoklar }\end{array}$ & $\begin{array}{l}\text { Girdi Faktörü } 2 \\
\text { Maddi Duran } \\
\text { Varlıklar }\end{array}$ & $\begin{array}{c}\text { Girdi Faktörü } 3 \\
\text { Öz Sermaye } \\
\text { (Azınlık Payı } \\
\text { Dahil) }\end{array}$ & $\begin{array}{c}\text { Girdi Faktörü } 4 \\
\text { Satışların Maliyeti } \\
(-)\end{array}$ \\
\hline Firma 1 & €4.434.936,00 & も6.912.335,00 & €23.186.050,00 & も17.530.256,00 \\
\hline Firma 2 & も113.113.000,00 & も109.575.000,00 & も205.399.000,00 & も176.818.000,00 \\
\hline Firma 3 & €10.954.160,00 & €567.355.002,00 & Ł228.860.881,00 & €133.230.098,00 \\
\hline Firma 4 & も111.105.886,00 & €28.694.312,00 & も362.410.723,00 & も428.965.004,00 \\
\hline $\begin{array}{l}\text { Firma } 5 \\
\text { Firma } 6\end{array}$ & $\begin{array}{c}€ 40.201 .877,00 \\
€ 4.825 .019,00\end{array}$ & $\begin{array}{c}€ 29.015 .437,00 \\
€ 5.588 .244,00\end{array}$ & $\begin{array}{c}\text { Ł128.190.670,00 } \\
\text { 10.560.009,00 }\end{array}$ & $\begin{array}{c}\text { Ł195.884.054,00 } \\
\text { Ł17.142.109,00 }\end{array}$ \\
\hline Firma 7 & も124.866.380,00 & も651.114.522,00 & も473.707.112,00 & も415.207.155,00 \\
\hline Firma 8 & €10.047.173,00 & €13.562.572,00 & も64.702.861,00 & も132.503.659,00 \\
\hline Firma 9 & も10.905.396,00 & €57.233.256,00 & €61.384.888,00 & も49.079.584,00 \\
\hline $\begin{array}{c}\ldots \\
\text { Firma } \\
144\end{array}$ & も138.691.658,00 & も103.328.491,00 & も141.125.311,00 & も190.725.102,00 \\
\hline $\begin{array}{l}\text { Firma } \\
145\end{array}$ & $\begin{array}{c}\text { €5.291.090.000 } \\
00\end{array}$ & $\begin{array}{c}\text { Ł12.303.437.000 } \\
00\end{array}$ & $\begin{array}{c}\text { も10.477.661.000 } \\
00\end{array}$ & $\begin{array}{c}\text { €47.734.212.000， } \\
00\end{array}$ \\
\hline $\begin{array}{l}\text { Firma } \\
146\end{array}$ & も564.685.465,00 & $\begin{array}{c}\text { Ł2.028.532.268,0 } \\
0\end{array}$ & $\begin{array}{c}\text { Ł2.695.903.154,0 } \\
0\end{array}$ & $\begin{array}{c}\text { Ł3.534.096.627,0 } \\
0\end{array}$ \\
\hline $\begin{array}{c}\text { Firma } \\
147\end{array}$ & も44.832.194,00 & も68.299.089,00 & も203.857.285,00 & Ł307.882.927,00 \\
\hline $\begin{array}{l}\text { Firma } \\
148 \\
\text { Firma }\end{array}$ & も222.341.158,00 & €68.002.892,00 & も195.674.191,00 & $\begin{array}{c}\text { も1.715.166.304,0 } \\
0\end{array}$ \\
\hline 149 & も40.874.508,00 & も143.631.623,00 & €304.813.222,00 & €178.233.731,00 \\
\hline $\begin{array}{c}\text { Firma } \\
150\end{array}$ & $\begin{array}{c}\text { €2.944.179.000 } \\
00\end{array}$ & $\begin{array}{c}\text { Ł2.366.014.000,0 } \\
0\end{array}$ & $\begin{array}{c}€ 2.278 .028 .000,0 \\
0\end{array}$ & $\begin{array}{c}\text { €9.673.251.000,0 } \\
0\end{array}$ \\
\hline $\begin{array}{l}\text { Firma } \\
151 \\
\text { Firma }\end{array}$ & も125.256.520,00 & も242.838.680,00 & も235.143.421,00 & も461.351.248,00 \\
\hline 152 & $€ 69.840 .586,00$ & $€ 47.020 .879,00$ & $€ 65.403 .737,00$ & $€ 225.518 .232,00$ \\
\hline
\end{tabular}

Kaynak: Finnet verilerinden derlenmiştir. İndirme Tarihi: 05 Nisan 2018

Sanayi işletmelerinin doğru yansıtabilmek amacıyla seçilen girdi faktörleri sırasıyla; stoklar, maddi duran varlıklar, özsermaye (azınlık payı dahil) ve satışların maliyetidir. Bu girdi unsurlarının seçilme nedeni sektörün yapısını doğru yansıtabilmektir. Hizmet işletmelerinden farklı olarak fiziki üretim yapmalarından dolayı stok önemli bir göstergedir. Yine, fiziki 


\section{Aşkın ÖZDAĞoĞLU}

üretim yapabilmek için maddi duran varlıklara yatırım yapılması gerekmektedir. Ayrıca, bu fiziki üretimi gerçekleştirebilmek için katlanılan üretim maliyetlerinin olabildiğince düşük tutulabilmesi bir başarı göstergesidir. Üretim maliyetini modele yansıtabilecek unsur da satışların maliyetidir. Girdi unsuru olarak belirtilen, stoklar, maddi duran varlıklar, özsermaye ve satışların maliyeti kısıtı kaynakları simgelemektedir. Sanayi işletmeleri bu kısıtı kaynakları en doğru şekilde kullanarak daha fazla çıktı elde etmeye çalışmaktadır. Bu çıktıların göstergesi de sırasıyla satış gelirleri ve brüt esas faaliyet karı/zararıdır. 152 sanayi işletmesinin girdi faktörlerine ilişkin değerleri sayfa kısıtı nedeniyle kısmi olarak Tablo 1'de gösterilmiştir. Sanayi işletmelerinin çıktı faktörlerine ilişkin değerlerin bir kısmı da Tablo 2'de verilmiştir.

\section{Tablo 2: Çıktı Değerleri}

\begin{tabular}{|c|c|c|}
\hline & Çıktı Faktörü 1 & Çıktı Faktörü 2 \\
\hline & Satış Gelirleri & Brüt Esas Faaliyet Karı/Zararı \\
\hline Firma 1 & €21.164.595,00 & €3.634.339,00 \\
\hline Firma 2 & €322.397.000,00 & Ł145.579.000,00 \\
\hline Firma 3 & も168.153.098,00 & も34.923.000,00 \\
\hline Firma 4 & も581.125.221,00 & も152.160.217,00 \\
\hline Firma 5 & Ł235.732.825,00 & も39.848.771,00 \\
\hline Firma 6 & も18.599.010,00 & も1.456.901,00 \\
\hline Firma 7 & €519.579.071,00 & Ł104.371.916,00 \\
\hline Firma 8 & Ł161.084.307,00 & €28.580.648,00 \\
\hline Firma 9 & も54.671.468,00 & も5.591.884,00 \\
\hline$\cdots$ & $\cdots$ & $\cdots$ \\
\hline Firma 144 & €235.258.862,00 & も44.533.760,00 \\
\hline Firma 145 & €53.948.110.000,00 & €6.213.898.000,00 \\
\hline Firma 146 & も4.811.032.525,00 & も1.276.935.898,00 \\
\hline Firma 147 & も436.452.287,00 & も128.569.360,00 \\
\hline Firma 148 & も1.805.706.332,00 & も90.540.028,00 \\
\hline Firma 149 & Ł252.526.159,00 & €74.292.428,00 \\
\hline Firma 150 & も12.100.938.000,00 & €2.427.687.000,00 \\
\hline Firma 151 & Ł795.685.790,00 & Ł334.334.542,00 \\
\hline Firma 152 & $€ 297.580 .363,00$ & も72.062.131,00 \\
\hline
\end{tabular}

Kaynak: Finnet verilerinden derlenmiştir. İndirme Tarihi: 05 Nisan 2018 


\section{BİST Sinai İşletmelerinin Gri Entropi-EATWIOS Bütünleşik Yaklaşımı ile Performans Değerlendirmesi}

Girdi faktörlerinin ağırlıklarını hesaplamak için kullanılan gri entropi yöntemi kapsamında ilk olarak normalleştirilmiş değerlerin hesaplanması gerekmektedir. Girdi faktörlerine ilişkin olarak hesaplanan normalleştirilmiş değerlerin kısmi gösterimi Tablo 3'te sunulduğu gibidir.

Çıktı unsurlarının ağırıklarını hesaplamak için de gri entropi yöntemi kapsamında ilk olarak normalleştirilmiş değerlerin hesaplanması gerekmektedir. Çıktı faktörlerine ilişkin olarak hesaplanan normalleştirilmiş değerlerin kısmi gösterimi de Tablo 4'te verilmiştir.

Gri entropi yönteminde normalleştirilmiş değerlerin hesaplanmasının ardından yapılması gereken işlem $W_{e}\left(z_{i j}\right)$ değerlerinin bulunmasıdır. Buna yönelik olarak girdi faktörleri ile ilgili $W_{e}\left(s_{i j}\right)$ değerlerinin kısmi gösterimi Tablo 5 'te; çıktı faktörleri ile ilgili $W_{e}\left(z_{i j}\right)$ değerlerinin kısmi gösterimi ise Tablo 6'da sunulmuştur.

İzleyen adımda entropi değerleri, toplam entropi, her bir girdi ve çıktı unsuruna ilişkin göreceli ağırlıklar ile normalize edilmiş ağırlık değerleri bulunmaktadır. Girdi unsurlarına ilişkin entropi değerleri, toplam entropi, her bir girdi ve çıktı unsuruna ilişkin göreceli ağırıklar ile normalize edilmiş ağırlık değerleri Tablo 7'de gösterilmiştir.

Tablo 7'de bulunan beta değerleri girdi faktörlerinin ağırlıklarını ifade etmektedir. Bu ağırlıklar EATWIOS yöntemi ile performans değerlendirme kısmında girdi olarak kullanılacaktır. Benzer süreç çıktı unsurlarına da uygulanarak entropi değerleri, toplam entropi, her bir girdi ve çıktı unsuruna ilişkin göreceli ağırlıklar ile normalize edilmiş ağırlık değerleri bulunmaktadır. Çıktı unsurlarına ilişkin entropi değerleri, toplam entropi, her bir girdi ve çıktı unsuruna ilişkin göreceli ağırıklar ile normalize edilmiş ağırlık değerleri de Tablo 8'de verilmiştir.

Gri entropi yöntemi ile her bir girdi ve çıktı faktörünün ağırıklarının bulunmasının ardından BİST Sınai kategorisinde yer alan 152 sanayi işletmesinin performans değerlendirmesini yapmak üzere EATWIOS yöntemi kapsamındaki işlemler yapılacaktır. Tablo 1 ve Tablo 2'de gösterilen değerler EATWIOS yönteminin de verileridir. Yöntemin ilk aşamasında farklı özelliklere sahip olan girdi ve çıtı unsurlarını analiz edebilmek amacı ile verileri normalleştirmek gerekmektedir. EATWIOS yönteminde bu normalleştirme işlemi vektör normalizasyonu ile yapılmaktadır. Yapılan bu işlem verileri birimi olmayan standart sayılara dönüştürmektedir. Böylece bu standart sayllar bütünleştirilebilir. Girdi unsurlarına uygulanan vektör normalizasyonu sonucunda bulunan değerler Tablo 9'da kısmi olarak gösterilmiştir. 


\section{Aşkın ÖZDAĞoĞLU}

Tablo 3: Girdi Faktörlerine İlişkin Normalleştirilmiş Değerler

\begin{tabular}{ccccc} 
& Stoklar & $\begin{array}{c}\text { Girdi Faktörü } 1 \\
\text { Maddi Duran } \\
\text { Varlıklar }\end{array}$ & $\begin{array}{c}\text { Girdi Faktörü 2 } \\
\text { Oirdi Faktörü 3 } 3 \\
\text { (Azınlık Payı } \\
\text { Dahil) }\end{array}$ & $\begin{array}{c}\text { Girdi Faktörü 4 } \\
\text { Satışların } \\
\text { Maliyeti (-) }\end{array}$ \\
\hline Firma 1 & 0,000109 & 0,000062 & 0,000170 & 0,000074 \\
Firma 2 & 0,002769 & 0,000986 & 0,001509 & 0,000745 \\
Firma 3 & 0,000268 & 0,005105 & 0,001681 & 0,000562 \\
Firma 4 & 0,002720 & 0,000258 & 0,002662 & 0,001808 \\
Firma 5 & 0,000984 & 0,000261 & 0,000942 & 0,000826 \\
Firma 6 & 0,000118 & 0,000050 & 0,000078 & 0,000072 \\
Firma 7 & 0,003056 & 0,005859 & 0,003479 & 0,001750 \\
Firma 8 & 0,000246 & 0,000122 & 0,000475 & 0,000559 \\
$\ldots$ & $\ldots$ & $\ldots$ & $\ldots$ & $\ldots$ \\
Firma 145 & 0,129513 & 0,110715 & 0,076956 & 0,201232 \\
Firma 146 & 0,013822 & 0,018254 & 0,019801 & 0,014899 \\
Firma 147 & 0,001097 & 0,000615 & 0,001497 & 0,001298 \\
Firma 148 & 0,005442 & 0,000612 & 0,001437 & 0,007231 \\
Firma 149 & 0,001001 & 0,001292 & 0,002239 & 0,000751 \\
Firma 150 & 0,072066 & 0,021291 & 0,016732 & 0,040779 \\
Firma 151 & 0,003066 & 0,002185 & 0,001727 & 0,001945 \\
Firma 152 & 0,001710 & 0,000423 & 0,000480 & 0,000951 \\
\hline
\end{tabular}


BİST Sinai İşletmelerinin Gri Entropi-EATWIOS Bütünleşik Yaklaşımı ile Performans Değerlendirmesi

Tablo 4: Çıktı Faktörlerine İliş̧in Normalleştirilmiş Değerler

\begin{tabular}{ccc} 
& Çıktı Faktörü 1 & $\begin{array}{c}\text { Çıktı Faktörü 2 } \\
\text { Brüt Esas Faaliyet } \\
\text { Karı/Zararı }\end{array}$ \\
\hline Satış Gelirleri & 0,000062 \\
Firma 1 & 0,000072 & 0,002490 \\
Firma 3 & 0,001091 & 0,000597 \\
Firma 4 & 0,000569 & 0,002602 \\
Firma 5 & 0,001966 & 0,000681 \\
Firma 6 & 0,000798 & 0,000025 \\
Firma 7 & 0,000063 & 0,001785 \\
Firma 8 & 0,001758 & 0,000489 \\
$\ldots$ & 0,000545 & $\ldots$ \\
Firma 145 & $\ldots$ & 0,106267 \\
Firma 146 & 0,182558 & 0,021838 \\
Firma 147 & 0,016280 & 0,002199 \\
Firma 148 & 0,001477 & 0,001548 \\
Firma 149 & 0,006110 & 0,001271 \\
Firma 150 & 0,000855 & 0,041517 \\
Firma 151 & 0,040949 & 0,005718 \\
Firma 152 & 0,002693 & 0,001232 \\
\hline
\end{tabular}




\section{Aşkın ÖZDAĞoĞLU}

\section{Tablo 5: Girdi Faktörlerine İlişkin $W_{e}\left(z_{\text {ifj }}\right)$ Değerleri}

Girdi Faktörü 1 Girdi Faktörü 2 Girdi Faktörü 3 Girdi Faktörü 4

\begin{tabular}{ccccc} 
& Stoklar & $\begin{array}{c}\text { Maddi Duran } \\
\text { Varlıklar }\end{array}$ & $\begin{array}{c}\text { Öz Sermaye } \\
\text { (Azınlık Payı } \\
\text { Dahil) }\end{array}$ & $\begin{array}{c}\text { Satışların } \\
\text { Maliyeti }(-)\end{array}$ \\
\hline Firma 1 & 0,000295 & 0,000169 & 0,000463 & 0,000201 \\
Firma 2 & 0,007502 & 0,002677 & 0,004094 & 0,002024 \\
Firma 3 & 0,000729 & 0,013794 & 0,004560 & 0,001526 \\
Firma 4 & 0,007369 & 0,000702 & 0,007213 & 0,004905 \\
Firma 5 & 0,002672 & 0,000710 & 0,002556 & 0,002243 \\
Firma 6 & 0,000321 & 0,000137 & 0,000211 & 0,000196 \\
Firma 7 & 0,008278 & 0,015817 & 0,009419 & 0,004748 \\
Firma 8 & 0,000668 & 0,000332 & 0,001291 & 0,001517 \\
$\ldots$ & $\ldots$ & $\ldots$ & $\ldots$ & $\ldots$ \\
Firma 145 & 0,300139 & 0,262812 & 0,190576 & 0,424119 \\
Firma 146 & 0,036960 & 0,048554 & 0,052570 & 0,039788 \\
Firma 147 & 0,002979 & 0,001669 & 0,004063 & 0,003523 \\
Firma 148 & 0,014699 & 0,001662 & 0,003900 & 0,019487 \\
Firma 149 & 0,002716 & 0,003508 & 0,006070 & 0,002041 \\
Firma 150 & 0,179551 & 0,056426 & 0,044585 & 0,105566 \\
Firma 151 & 0,008304 & 0,005925 & 0,004685 & 0,005275 \\
Firma 152 & 0,004638 & 0,001150 & 0,001305 & 0,002581 \\
\hline
\end{tabular}


BİST Sinai İşletmelerinin Gri Entropi-EATWIOS Bütünleşik Yaklaşımı ile Performans Değerlendirmesi

Tablo 6: Çıktı Faktörlerine İlişkin $W_{e}\left(z_{i j}\right)$ Değerleri

\begin{tabular}{ccc} 
& $\begin{array}{c}\text { Çıktı Faktörü 1 } \\
\text { Satış Gelirleri }\end{array}$ & $\begin{array}{c}\text { Çıtı Faktörü 2 } \\
\text { Brüt Esas Faaliyet } \\
\text { Karı/Zararı }\end{array}$ \\
\hline Firma 1 & 0,000195 & 0,000169 \\
Firma 2 & 0,002962 & 0,006748 \\
Firma 3 & 0,001546 & 0,001622 \\
Firma 4 & 0,005333 & 0,007052 \\
Firma 5 & 0,002166 & 0,001851 \\
Firma 6 & 0,000171 & 0,000068 \\
Firma 7 & 0,004769 & 0,004842 \\
Firma 8 & 0,001481 & 0,001328 \\
$\ldots$ & $\ldots$ & $\ldots$ \\
Firma 145 & 0,394601 & 0,253680 \\
Firma 146 & 0,043406 & 0,057837 \\
Firma 147 & 0,004008 & 0,005961 \\
Firma 148 & 0,016490 & 0,004201 \\
Firma 149 & 0,002321 & 0,003448 \\
Firma 150 & 0,105983 & 0,107380 \\
Firma 151 & 0,007296 & 0,015437 \\
Firma 152 & 0,002734 & 0,003345 \\
\hline
\end{tabular}

Tablo 7: Girdi Faktörlerine İlişkin Ek, Toplam Entropi, Lambda K ve Beta K Değerleri

\begin{tabular}{|c|c|c|c|c|}
\hline & $\begin{array}{c}\text { Girdi Faktörü } \\
1 \\
\text { Stoklar }\end{array}$ & $\begin{array}{c}\text { Girdi Faktörü } \\
2 \\
\text { Maddi Duran } \\
\text { Varlıklar }\end{array}$ & $\begin{array}{c}\text { Girdi Faktörü } \\
3 \\
\text { Öz Sermaye } \\
\text { (Azınlık Payı } \\
\text { Dahil) }\end{array}$ & $\begin{array}{c}\text { Girdi } \\
\text { Faktörü } 4 \\
\text { Satışların } \\
\text { Maliyeti (-) }\end{array}$ \\
\hline$e_{j}$ & 0,983633 & 0,993334 & 0,985801 & 0,965822 \\
\hline$E$ & 3,928590 & & & \\
\hline$\lambda_{j}$ & 0,229197 & 0,093349 & 0,198840 & 0,478615 \\
\hline$\beta_{j}$ & 0,229197 & 0,093349 & 0,198840 & 0,478615 \\
\hline
\end{tabular}




\section{Aşkın ÖZDAĞoĞLU}

Tablo 8: Çıktı Faktörlerine İlişkin Ek, Toplam Entropi, Lambda K ve Beta K Değerleri

\begin{tabular}{ccc} 
& Çıktı Faktörü 1 & $\begin{array}{c}\text { Çıktı Faktörü 2 } \\
\text { Brüt Esas Faaliyet } \\
\text { Karı/Zararı }\end{array}$ \\
\hline$e_{j}$ & 1,947135 & 1,972275 \\
$E$ & 3,919410 & \\
$\lambda_{j}$ & 0,493451 & 0,506549 \\
$\beta_{j}$ & 0,493451 & 0,506549 \\
\hline
\end{tabular}

Tablo 9: Girdi Faktörlerine Uygulanan Vektör Normalizasyonu İşlemi

Girdi Faktörü 1 Girdi Faktörü 2 Girdi Faktörü 3 Girdi Faktörü 4

\begin{tabular}{ccccc} 
& Stoklar & $\begin{array}{c}\text { Maddi Duran } \\
\text { Varlıklar }\end{array}$ & $\begin{array}{c}\text { Öz Sermaye } \\
\text { (Azınlık Payı } \\
\text { Dahil) }\end{array}$ & $\begin{array}{c}\text { Satışların } \\
\text { Maliyeti (-) }\end{array}$ \\
\hline Firma 1 & 0,000471 & 0,000294 & 0,000752 & 0,000282 \\
Firma 2 & 0,012011 & 0,004657 & 0,006658 & 0,002843 \\
Firma 3 & 0,001163 & 0,024112 & 0,007419 & 0,002142 \\
Firma 4 & 0,011798 & 0,001219 & 0,011748 & 0,006897 \\
Firma 5 & 0,004269 & 0,001233 & 0,004155 & 0,003149 \\
$\ldots$ & $\ldots$ & $\ldots$ & $\ldots$ & $\ldots$ \\
Firma 147 & 0,004761 & 0,002903 & 0,006608 & 0,004950 \\
Firma 148 & 0,023610 & 0,002890 & 0,006343 & 0,027577 \\
Firma 149 & 0,004340 & 0,006104 & 0,009881 & 0,002866 \\
Firma 150 & 0,312632 & 0,100552 & 0,073845 & 0,155528 \\
Firma 151 & 0,013301 & 0,010320 & 0,007622 & 0,007418 \\
Firma 152 & 0,007416 & 0,001998 & 0,002120 & 0,003626 \\
\hline
\end{tabular}

Girdi faktörlerine uygulanan bu normalleştirme işleminin çıktı unsurlarına da uygulanması gerekmektedir. Çıktı unsurlarına uygulanan vektör normalizasyonu işlemlerinin sonuçları kısmi olarak Tablo $10^{\prime} \mathrm{da}$ verilmiştir. 
BİST Sinai İşletmelerinin Gri Entropi-EATWIOS Bütünleşik Yaklaşımı ile Performans Değerlendirmesi

Tablo 10: Çıktı Faktörlerine Uygulanan Vektör Normalizasyonu İşlemi

\begin{tabular}{ccc} 
& Çıktı Faktörü 1 & $\begin{array}{c}\text { Çıtı Faktörü 2 } \\
\text { Büt Esas Faaliyet } \\
\text { Karı/Zararı }\end{array}$ \\
\hline Satış Gelirleri & 0,000276 \\
Firma 1 & 0,000288 & 0,011044 \\
Firma 3 & 0,004384 & 0,002649 \\
Firma 4 & 0,002287 & 0,011543 \\
Firma 5 & 0,007903 & 0,003023 \\
Firma 6 & 0,003206 & 0,000111 \\
Firma 7 & 0,000253 & 0,007918 \\
Firma 8 & 0,007066 & 0,002168 \\
$\ldots$ & 0,002191 & $\ldots$ \\
Firma 145 & $\ldots$ & 0,471388 \\
Firma 146 & 0,733661 & 0,096869 \\
Firma 147 & 0,065427 & 0,009753 \\
Firma 148 & 0,005935 & 0,006868 \\
Firma 149 & 0,024557 & 0,005636 \\
Firma 150 & 0,003434 & 0,184165 \\
Firma 151 & 0,164565 & 0,025363 \\
Firma 152 & 0,010821 & 0,005467 \\
\hline
\end{tabular}

Vektör normalizasyonu yardımıyla yapılan standartlaştırma işleminin ardından belirli bir girdi unsuru açısından her bir firmayı bu girdi unsuru açısından en iyi durumdaki firmayla kıyaslayarak Eşitlik 14'e göre işlem yapılmaktadır. Girdi unsurları açısından bu işlemin sonuçları Tablo 11 'de kısmi olarak gösterilmiştir.

\section{Tablo 11: Girdi Faktörleri Kıyaslama}

Girdi Faktörü 1 Girdi Faktörü 2 Girdi Faktörü 3 Girdi Faktörü Stoklar Maddi Duran Öz Sermaye Satışların

\begin{tabular}{ccccc} 
& Stoklar & $\begin{array}{c}\text { Maddi Duran } \\
\text { Varlıklar }\end{array}$ & $\begin{array}{c}\text { Öz Sermaye } \\
\text { (Azınlık Payı } \\
\text { Dahil) }\end{array}$ & $\begin{array}{c}\text { Satısların } \\
\text { Maliyeti }(-)\end{array}$ \\
\hline Firma 1 & 1,000471 & 1,000292 & 1,001115 & 1,000281 \\
Firma 2 & 1,012011 & 1,004655 & 1,007021 & 1,002842 \\
Firma 3 & 1,001163 & 1,024110 & 1,007782 & 1,002141
\end{tabular}




\section{Aşkın ÖZDAĞoĞLU}

Girdi Faktörü 1 Girdi Faktörü 2 Girdi Faktörü 3 Girdi Faktörü

Stoklar Maddi Duran Öz Sermaye $\quad 4$ Varlıklar (Azınlık Payı Maliyeti (-)

\begin{tabular}{ccccc} 
& & \multicolumn{3}{c}{ Dahil) } \\
\hline Firma 4 & 1,011798 & 1,001218 & 1,012111 & 1,006896 \\
Firma 5 & 1,004269 & 1,001231 & 1,004519 & 1,003149 \\
Firma 6 & 1,000512 & 1,000236 & 1,000705 & 1,000275 \\
Firma 7 & 1,013259 & 1,027670 & 1,015719 & 1,006675 \\
Firma 8 & 1,001067 & 1,000574 & 1,002461 & 1,002130
\end{tabular}

\begin{tabular}{ccccc}
$\ldots$ & $\ldots$ & $\ldots$ & $\ldots$ & $\ldots$ \\
Firma 145 & 1,561842 & 1,522878 & 1,340008 & 1,767477 \\
Firma 146 & 1,059962 & 1,086208 & 1,087754 & 1,056821 \\
Firma 147 & 1,004761 & 1,002901 & 1,006971 & 1,004950 \\
Firma 148 & 1,023610 & 1,002888 & 1,006706 & 1,027576 \\
Firma 149 & 1,004340 & 1,006102 & 1,010244 & 1,002865 \\
Firma 150 & 1,312632 & 1,100550 & 1,074208 & 1,155527 \\
Firma 151 & 1,013301 & 1,010318 & 1,007986 & 1,007417 \\
Firma 152 & 1,007416 & 1,001996 & 1,002483 & 1,003625 \\
\hline
\end{tabular}

Belirli bir çıktı unsuru açısından her bir firmayı bu çıktı unsuru açısından en iyi durumdaki firmayla kıyaslayarak Eşitlik $15^{\prime} \mathrm{e}$ göre işlem yapılmaktadır. Çıktı unsurları açısından bu işlemin sonuçları Tablo 12 'de kısmi olarak gösterilmiştir.

\section{Tablo 12: Çıktı Faktörleri Kıyaslama}

\begin{tabular}{ccc} 
& Çıktı Faktörü 1 & $\begin{array}{c}\text { Cıktı Faktörü 2 } \\
\text { Brüt Esas Faaliyet } \\
\text { Karı/Zararı }\end{array}$ \\
\hline Satış Gelirleri & 0,266627 & 0,506714 \\
Firma 1 & 0,270723 & 0,517482 \\
Firma 3 & 0,268625 & 0,509088 \\
Firma 4 & 0,274242 & 0,517981 \\
Firma 5 & 0,269545 & 0,509461 \\
Firma 6 & 0,266592 & 0,506549 \\
Firma 7 & 0,273405 & 0,514356 \\
Firma 8 & 0,268529 & 0,508607 \\
$\ldots$ & $\ldots$ & $\ldots$ \\
Firma 145 & 1,000000 & 0,977826
\end{tabular}


BİST Sinai İşletmelerinin Gri Entropi-EATWIOS Bütünleşik Yaklaşımı ile Performans Değerlendirmesi

\begin{tabular}{ccc} 
& Çıktı Faktörü 1 & $\begin{array}{c}\text { Çıktı Faktörü 2 } \\
\text { Brüt Esas Faaliyet } \\
\text { Karı/Zararı }\end{array}$ \\
\hline Satış Gelirleri & 0,331766 & 0,603307 \\
Firma 146 147 & 0,272274 & 0,516192 \\
Firma 148 & 0,290895 & 0,513307 \\
Firma 149 & 0,269773 & 0,512074 \\
Firma 150 & 0,430904 & 0,690603 \\
Firma 151 & 0,277160 & 0,531801 \\
Firma 152 & 0,270386 & 0,511905 \\
\hline
\end{tabular}

Girdi ve çıktı unsurlarının sanayi işletmelerinin performansı üzerindeki etkisi farklı olduğundan dolayı Tablo $11^{\prime}$ deki değerlerin girdi unsurlarının ağırlıkları ile Tablo 12'deki değerlerin de çıtı unsurlarının ağırlıkları ile çarpılması gerekmektedir. Bu ağırlık vektörünün hesaplanmasında gri entropi yöntemi kullanıımıştır. Gri entropi yöntemine göre bulunan girdi unsurlarının ağırlıkları Tablo 7'de, çıktı unsurlarının ağırıkları ise Tablo 8'de verilmişti. Girdi unsurlarına ilişkin ağırlıklandırılmış kıyaslama değerleri Tablo 13 'te kısmi olarak sunulmuştur. Çıktı unsurlarına ilişkin ağırlıklı kıyaslama değerleri de Tablo 14'te verilmiştir.

\section{Tablo 13: Girdi Faktörleri Ağırlıklı Kıyaslama}

Girdi Faktörü 1 Girdi Faktörü 2 Girdi Faktörü 3 Girdi Faktörü

\begin{tabular}{ccccc} 
& Stoklar & $\begin{array}{c}\text { Maddi Duran } \\
\text { Varlıklar }\end{array}$ & $\begin{array}{c}\text { Öz Sermaye } \\
\text { (Azınlık Payı } \\
\text { Dahil) }\end{array}$ & $\begin{array}{c}\text { Satışların } \\
\text { Maliyeti (-) }\end{array}$ \\
\hline Firma 1 & 0,229305 & 0,093376 & 0,199061 & 0,478749 \\
Firma 2 & 0,231950 & 0,093783 & 0,200236 & 0,479975 \\
Firma 3 & 0,229464 & 0,095599 & 0,200387 & 0,479640 \\
Firma 4 & 0,231901 & 0,093462 & 0,201248 & 0,481915 \\
Firma 5 & 0,230175 & 0,093464 & 0,199738 & 0,480122 \\
Firma 6 & 0,229314 & 0,093371 & 0,198980 & 0,478746 \\
Firma 7 & 0,232236 & 0,095932 & 0,201965 & 0,481809 \\
$\ldots$ & $\ldots$ & $\ldots$ & $\ldots$ & $\ldots$ \\
Firma 146 & 0,242940 & 0,101396 & 0,216289 & 0,505810 \\
Firma 147 & 0,230288 & 0,093619 & 0,200226 & 0,480984 \\
Firma 148 & 0,234608 & 0,093618 & 0,200173 & 0,491813
\end{tabular}




\section{Aşkın ÖZDAĞoĞLU}

Girdi Faktörü 1 Girdi Faktörü 2 Girdi Faktörü 3 Girdi Faktörü

\begin{tabular}{lcccc} 
& Stoklar & $\begin{array}{c}\text { Maddi Duran } \\
\text { Varlıklar }\end{array}$ & $\begin{array}{c}\text { Öz Sermaye } \\
\text { (Azınlık Payı } \\
\text { Dahil) }\end{array}$ & $\begin{array}{c}4 \\
\text { Satışların } \\
\text { Maliyeti (-) }\end{array}$ \\
\hline Firma 149 & 0,230192 & 0,093918 & 0,200877 & 0,479986 \\
Firma 150 & 0,300851 & 0,102735 & 0,213595 & 0,553052 \\
Firma 151 & 0,232245 & 0,094312 & 0,200428 & 0,482164 \\
Firma 152 & 0,230897 & 0,093535 & 0,199334 & 0,480350 \\
\hline
\end{tabular}

\section{Tablo 14: Çıktı Faktörleri Ağırııkı Kıyaslama}

\begin{tabular}{ccc} 
& Çıktı Faktörü 1 & $\begin{array}{c}\text { Çıktı Faktörü 2 } \\
\text { Brüt Esas Faaliyet } \\
\text { Karı/Zararı }\end{array}$ \\
\hline Firma 1 & 0,131567 & 0,256676 \\
Firma 2 & 0,133589 & 0,262130 \\
Firma 3 & 0,132553 & 0,257878 \\
Firma 4 & 0,135325 & 0,262383 \\
Firma 5 & 0,133007 & 0,258067 \\
Firma 6 & 0,131550 & 0,256592 \\
Firma 7 & 0,134912 & 0,260547 \\
Firma 8 & 0,132506 & 0,257634 \\
$\ldots$ & $\ldots$ & $\ldots$ \\
Firma 145 & 0,493451 & 0,495317 \\
Firma 146 & 0,163710 & 0,305605 \\
Firma 147 & 0,134354 & 0,261476 \\
Firma 148 & 0,143543 & 0,260015 \\
Firma 149 & 0,133120 & 0,259391 \\
Firma 150 & 0,212630 & 0,349824 \\
Firma 151 & 0,136765 & 0,269383 \\
Firma 152 & 0,133422 & 0,259305 \\
\hline
\end{tabular}

Sırasıyla, vektör normalizasyonu ile standartlaştırılan, en iyi durumdaki firma ile kıyaslanan ve gri entropiden bulunan ağırlık vektörleri sayesinde ağırlıklandırılan değerler artık bütünleştirilebilir duruma gelmiştir. Bu amaçla, girdi ve çıktı unsurlarının bütünleşik değerleri hesaplanmıştır. Bulunan değerler kısmi olarak Tablo 15'te verilmiştir. 
BİST Sinai İşletmelerinin Gri Entropi-EATWIOS Bütünleşik Yaklaşımı ile Performans Değerlendirmesi

Tablo 15: Girdi ve Çıktı Faktörleri Bütünleşik Değerleri

\begin{tabular}{ccc} 
& Girdiler & Çıtıllar \\
\hline Firma 1 & 1,000491 & 0,388243 \\
Firma 2 & 1,005944 & 0,395719 \\
Firma 3 & 1,005090 & 0,390431 \\
Firma 4 & 1,008527 & 0,397708 \\
Firma 5 & 1,003499 & 0,391074 \\
Firma 6 & 1,000411 & 0,388142 \\
Firma 7 & 1,011942 & 0,395458 \\
Firma 8 & 1,001807 & 0,390140 \\
$\ldots$ & $\ldots$ & $\ldots$ \\
Firma 145 & 1,612515 & 0,988768 \\
Firma 146 & 1,066435 & 0,469315 \\
Firma 147 & 1,005117 & 0,395830 \\
Firma 148 & 1,020213 & 0,403558 \\
Firma 149 & 1,004973 & 0,392510 \\
Firma 150 & 1,170234 & 0,562454 \\
Firma 151 & 1,009149 & 0,406148 \\
Firma 152 & 1,004115 & 0,392727 \\
\hline
\end{tabular}

Çıktı unsurlarının bütünleşik değerinin, girdi unsurlarının bütünleşik değerine oranlanması ile her bir sanayi işletmesinin performansı hesaplanabilmektedir. Eşitlik 18'e göre bulunan performans değerleri ve bu firmaların 152 sanayi işletmesi içindeki sırası Tablo 16'da verilmiştir.

Tablo 16: Sanayi İşletmelerinin Performans Değerleri ve Sıralamadaki Yerleri

\begin{tabular}{ccc} 
& Performans Değerleri & Siralama \\
\hline Firma 1 & 0,388052 & 140 \\
Firma 2 & 0,393380 & 57 \\
Firma 3 & 0,388454 & 125 \\
Firma 4 & 0,394345 & 52 \\
Firma 5 & 0,389711 & 94 \\
Firma 6 & 0,387982 & 145 \\
Firma 7 & 0,390791 & 83
\end{tabular}




\section{Aşkın ÖZDAĞoĞLU}

Performans Değerleri

Sıralama

\begin{tabular}{|c|c|c|}
\hline Firma 8 & 0,389437 & 102 \\
\hline Firma 9 & 0,388024 & 141 \\
\hline Firma 10 & 0,395072 & 49 \\
\hline Firma 11 & 0,392321 & 61 \\
\hline Firma 12 & 0,412921 & 18 \\
\hline Firma 13 & 0,386456 & 152 \\
\hline Firma 14 & 0,389821 & 93 \\
\hline Firma 15 & 0,391417 & 70 \\
\hline Firma 16 & 0,389337 & 105 \\
\hline Firma 17 & 0,388542 & 122 \\
\hline Firma 18 & 0,389494 & 98 \\
\hline Firma 19 & 0,390689 & 84 \\
\hline Firma 20 & 0,389963 & 92 \\
\hline Firma 21 & 0,387918 & 146 \\
\hline Firma 22 & 0,391219 & 77 \\
\hline Firma 23 & 0,392622 & 59 \\
\hline Firma 24 & 0,390816 & 82 \\
\hline Firma 25 & 0,387786 & 150 \\
\hline Firma 26 & 0,388874 & 109 \\
\hline Firma 27 & 0,531445 & 4 \\
\hline Firma 28 & 0,401560 & 32 \\
\hline Firma 29 & 0,387839 & 148 \\
\hline Firma 30 & 0,392277 & 62 \\
\hline Firma 31 & 0,390575 & 86 \\
\hline Firma 32 & 0,389402 & 103 \\
\hline Firma 33 & 0,397192 & 41 \\
\hline Firma 34 & 0,388364 & 130 \\
\hline Firma 35 & 0,389465 & 100 \\
\hline Firma 36 & 0,388191 & 134 \\
\hline Firma 37 & 0,390190 & 90 \\
\hline Firma 38 & 0,392975 & 58 \\
\hline Firma 39 & 0,387987 & 144 \\
\hline Firma 40 & 0,387995 & 142 \\
\hline Firma 41 & 0,388364 & 131 \\
\hline Firma 42 & 0,392221 & 63 \\
\hline
\end{tabular}

291 
BİST Sinai İşletmelerinin Gri Entropi-EATWIOS Bütünleşik Yaklaşımı ile Performans Değerlendirmesi

\begin{tabular}{|c|c|c|}
\hline & Performans Değerleri & Siralama \\
\hline Firma 43 & 0,391739 & 65 \\
\hline Firma 44 & 0,396493 & 44 \\
\hline Firma 45 & 0,387988 & 143 \\
\hline Firma 46 & 0,388187 & 135 \\
\hline Firma 47 & 0,389467 & 99 \\
\hline Firma 48 & 0,388174 & 136 \\
\hline Firma 49 & 0,397950 & 40 \\
\hline Firma 50 & 0,395039 & 50 \\
\hline Firma 51 & 0,424167 & 13 \\
\hline Firma 52 & 0,390335 & 88 \\
\hline Firma 53 & 0,387829 & 149 \\
\hline Firma 54 & 0,413462 & 17 \\
\hline Firma 55 & 0,391299 & 73 \\
\hline Firma 56 & 0,391299 & 73 \\
\hline Firma 57 & 0,391299 & 73 \\
\hline Firma 58 & 0,547382 & 3 \\
\hline Firma 59 & 0,400485 & 34 \\
\hline Firma 60 & 0,411669 & 20 \\
\hline Firma 61 & 0,391500 & 69 \\
\hline Firma 62 & 0,388983 & 108 \\
\hline Firma 63 & 0,412467 & 19 \\
\hline Firma 64 & 0,617374 & 1 \\
\hline Firma 65 & 0,388573 & 120 \\
\hline Firma 66 & 0,391574 & 67 \\
\hline Firma 67 & 0,391001 & 81 \\
\hline Firma 68 & 0,388452 & 126 \\
\hline Firma 69 & 0,388483 & 124 \\
\hline Firma 70 & 0,434617 & 12 \\
\hline Firma 71 & 0,391390 & 71 \\
\hline Firma 72 & 0,416277 & 16 \\
\hline Firma 73 & 0,389564 & 97 \\
\hline Firma 74 & 0,388673 & 114 \\
\hline Firma 75 & 0,387874 & 147 \\
\hline Firma 76 & 0,402391 & 30 \\
\hline
\end{tabular}




\section{Aşkın ÖZDAĞoĞLU}

Performans Değerleri

Sıralama

\begin{tabular}{|c|c|c|}
\hline Firma 77 & 0,389678 & 95 \\
\hline Firma 78 & 0,396222 & 46 \\
\hline Firma 79 & 0,388234 & 133 \\
\hline Firma 80 & 0,500136 & 6 \\
\hline Firma 81 & 0,388431 & 127 \\
\hline Firma 82 & 0,401716 & 31 \\
\hline Firma 83 & 0,388764 & 111 \\
\hline Firma 84 & 0,392124 & 64 \\
\hline Firma 85 & 0,400281 & 35 \\
\hline Firma 86 & 0,389464 & 101 \\
\hline Firma 87 & 0,400916 & 33 \\
\hline Firma 88 & 0,396961 & 42 \\
\hline Firma 89 & 0,389025 & 107 \\
\hline Firma 90 & 0,389632 & 96 \\
\hline Firma 91 & 0,399642 & 37 \\
\hline Firma 92 & 0,393629 & 55 \\
\hline Firma 93 & 0,399150 & 38 \\
\hline Firma 94 & 0,388095 & 139 \\
\hline Firma 95 & 0,507375 & 5 \\
\hline Firma 96 & 0,388262 & 132 \\
\hline Firma 97 & 0,390266 & 89 \\
\hline Firma 98 & 0,389210 & 106 \\
\hline Firma 99 & 0,391113 & 80 \\
\hline Firma 100 & 0,407176 & 27 \\
\hline Firma 101 & 0,388153 & 137 \\
\hline Firma 102 & 0,391221 & 76 \\
\hline Firma 103 & 0,397967 & 39 \\
\hline Firma 104 & 0,388642 & 115 \\
\hline Firma 105 & 0,388140 & 138 \\
\hline Firma 106 & 0,396929 & 43 \\
\hline Firma 107 & 0,394590 & 51 \\
\hline Firma 108 & 0,391190 & 78 \\
\hline Firma 109 & 0,390024 & 91 \\
\hline Firma 110 & 0,407728 & 25 \\
\hline Firma 111 & 0,391529 & 68 \\
\hline
\end{tabular}

293 
BİST Sinai İşletmelerinin Gri Entropi-EATWIOS Bütünleşik Yaklaşımı ile Performans Değerlendirmesi

\begin{tabular}{|c|c|c|}
\hline & Performans Değerleri & Sıralama \\
\hline Firma 112 & 0,390598 & 85 \\
\hline Firma 113 & 0,403254 & 28 \\
\hline Firma 114 & 0,409585 & 21 \\
\hline Firma 115 & 0,409585 & 21 \\
\hline Firma 116 & 0,409585 & 21 \\
\hline Firma 117 & 0,388405 & 128 \\
\hline Firma 118 & 0,392379 & 60 \\
\hline Firma 119 & 0,388595 & 118 \\
\hline Firma 120 & 0,393416 & 56 \\
\hline Firma 121 & 0,396423 & 45 \\
\hline Firma 122 & 0,394116 & 53 \\
\hline Firma 123 & 0,408880 & 24 \\
\hline Firma 124 & 0,389395 & 104 \\
\hline Firma 125 & 0,388602 & 117 \\
\hline Firma 126 & 0,461842 & 9 \\
\hline Firma 127 & 0,388615 & 116 \\
\hline Firma 128 & 0,395074 & 48 \\
\hline Firma 129 & 0,386802 & 151 \\
\hline Firma 130 & 0,388393 & 129 \\
\hline Firma 131 & 0,388580 & 119 \\
\hline Firma 132 & 0,407214 & 26 \\
\hline Firma 133 & 0,399917 & 36 \\
\hline Firma 134 & 0,388508 & 123 \\
\hline Firma 135 & 0,388705 & 113 \\
\hline Firma 136 & 0,391358 & 72 \\
\hline Firma 137 & 0,418833 & 14 \\
\hline Firma 138 & 0,416991 & 15 \\
\hline Firma 139 & 0,388564 & 121 \\
\hline Firma 140 & 0,391589 & 66 \\
\hline Firma 141 & 0,495004 & 7 \\
\hline Firma 142 & 0,435357 & 11 \\
\hline Firma 143 & 0,388737 & 112 \\
\hline Firma 144 & 0,388827 & 110 \\
\hline Firma 145 & 0,613184 & 2 \\
\hline
\end{tabular}




\section{Aşkın ÖZDAĞoĞLU}

\begin{tabular}{ccc} 
& Performans Değerleri & Siralama \\
\hline Firma 146 & 0,440078 & 10 \\
Firma 147 & 0,393815 & 54 \\
Firma 148 & 0,395562 & 47 \\
Firma 149 & 0,390568 & 87 \\
Firma 150 & 0,480634 & 8 \\
Firma 151 & 0,402466 & 29 \\
Firma 152 & 0,391118 & 79 \\
\hline
\end{tabular}

Tüm girdi ve çıktı unsurları bir arada incelendiğinde BİST Sınai kategorisinde yer alan 152 firma arasında en yüksek performans değerine sahip olan firmanın 0,617374 değeri ile 64 numaralı firma olduğu görülmektedir. Bu firmayı 0,613184 değeri ile 145 numaralı firma takip etmektedir.

\section{SONUÇ}

Yoğun rekabet ortamında firmaların hayatta kalabilmek için kendi durumlarını sürekli olarak gözden geçirmeleri vazgeçilmez bir zorunluluktur. Firmaların performanslarını tespit edebilmesindeki zorluklardan birisi ise performans göstergelerinin çok çeşitli olmasıdır. Ayrıca bu göstergelerin firma başarısı üzerindeki etkileri de aynı oranda olmayabilmektedir. İşte bu tür zorluklara çözüm getirmek üzere çeşitli çok ölçütlü karar verme yöntemleri geliştirilmiştir. Performans değerlendirmesinde farklı unsurları analiz eden yöntemlerden birisi de EATWIOS yöntemidir. Performans göstergelerin firma başarısı üzerindeki etkilerinin farklı olması sorununa yönelik olarak getirilen çözüm önerilen birisi de gri entropi yöntemidir. Bu bağlamda, çalışma kapsamında gri entropi ile EATWIOS yöntemlerinin birlikte kullanıldığı bir çözüm önerisi getirilmiştir. Bu çalışma kapsamında öncelikle gri entropi ve EATWIOS yöntemleri ile ilgili literatür incelemesi yapılmıştır. Literatür incelemesinde gri entropi yönteminin işletme kararlarının alınmasında olduğu gibi, metalürji, optik ve gıda gibi birçok alanda uygulanabildiği görülmüştür. EATWIOS yönteminin de işletmelerin performanslarının değerlendirilmesinde kullanıldığı ancak bu konuda literatürün zengin olmadığı görülmüştür. Bu çalışmanın diğer bir motivasyon unsuru da yöntemin yeni yeni kullanılmaya başlayan ve henüz yaygınlaşmayan bir yöntem olmasıdır. Çalışma içeriğinde, literatür incelemesinin ardından sırasıyla gri entropi ve EATWIOS yöntemleri matematiksel ifadeler ile 


\section{BİST Sinai İşletmelerinin Gri Entropi-EATWIOS Bütünleşik Yaklaşımı ile Performans Değerlendirmesi}

açıklanmışıır. Daha sonra uygulama kısmına geçilmiş ve BİST Sınai kategorisinde yer alan 152 firmanın girdi ve çıktı unsurları veri seti olarak toplanarak analizler gerçekleştirilmiştir.

Analiz kapsamında, BİST Sınai kategorisinde yer alan 152 sanayi işletmesinin tüm verileri Finnet veri tabanından indirilmiş ve analize tabi olan kriterlere ilişkin unsurların değerleri düzenlenmiştir. Sanayi işletmelerini doğru yansıtabilmek amacıyla sektör yapısına uygun girdi ve çıktı unsurları belirlenmeye çalışılmışıı. Bu amaca yönelik olarak seçilen girdi faktörleri sırasıyla; stoklar, maddi duran varlıklar, özsermaye (azınlık payı dahil) ve satışların maliyetidir. Sanayi işletmeleri fiziki üretim yaptıklarından stok bulundurmak zorunda kalmakta ve bu fiziki üretimi yapabilmek için maddi duran varlıklara yatırım yapmaları gerekmektedir. Bunun yanında, bu fiziki üretimi gerçekleştirebilmek için katlanılan direkt ilk madde malzeme, direkt işçilik ve genel üretim giderlerinin olabildiğince düşük tutulabilmesi bir başarı göstergesidir. Bu maliyetleri modele yansıtabilecek unsur da satışların maliyetidir. Girdi unsuru olarak belirtilen, stoklar, maddi duran varlıklar, özsermaye ve satışların maliyeti kısıtı kaynakları simgelemektedir. Sanayi işletmeleri bu kısıtı kaynakları en doğru şekilde kullanarak daha fazla çıktı elde etmeye çalışmaktadır. Bu çıktıların göstergesi de sırasıyla satış gelirleri ve brüt esas faaliyet karı/zararıdır. Bu doğrultuda hazırlanan modelde öncelikle bu girdi ve çıktı unsurlarının ağırlıkları gri entropi yöntemi ile bulunmuş ve EATWIOS yöntemi ile performans değerleri hesaplanmıştır. Elde edilen sonuçlar incelendiğinde, 0,6 performans değerini aşan sadece iki sanayi işletmesi görülmektedir. Bunlar sırasıyla firma 64 ve firma 145'tir. Bu iki firmanın ardından 0,5 ile 0,6 değerleri arasında performans değerine sahip olan dört sanayi işletmesi bulunmaktadır. Bu firmalar da sırasıyla firma 58, 27, 95 ve 80 'dir. Yine sonuçlar incelendiğinde, kaynaklarını tam olarak etkin kullanamayıp 0,4 değerinin altında kalan 117 sanayi işletmesi olduğu görülmektedir. Gelecek çalışmalar olarak, kullanılan bu yöntemlerin, sektörlerin kendine has yapısı dikkate alınarak belirlenecek girdi ve çıtı unsurları ile metalurji ve gıda gibi farklı sektörlere veya BİST metal, BİST makine gibi farklı endekslere uyarlanarak performans analizlerinde kullanılabilmesi mümkündür. 


\section{Aşkın ÖZDAĞoĞLU}

\section{KAYNAKÇA}

Bansal, A., Singh, R., Issar, S. ve Varkey, J. (2014). Evaluation of Vendors Ranking by EATWOS Approach. Journal of Advances in Management Research, 11 (3), 290-311.

Bhattacharya, D ve Bepari, B. (2014). Feasibility Study of Recycled Polypropylene Through Multi Response Optimization of İnjection Moulding Parameters Using Grey Relational Analysis. Procedia Engineering: 12th Global Congress on Manufacturing and Management, 97 (1), 186 - 196.

Chen, K, Kao, M., Huang, S., Li, C., Cheng, C., Wu, S. ve Wu, Z. (2017). Bipolar Switching Properties and Electrical Conduction Mechanism of Manganese Oxide RRAM Devices. Ceramics International. 43 (1), 253-257.

Cheng, J. ve Sun, D. (2015). Data Fusion and Hyperspectral Imaging in Tandem with Least Squares-Support Vector Machine for Prediction of Sensory Quality Index Scores of Fish Fillet. LWT - Food Science and Technology. 63 (1), 892-898.

Chou, J. ve Tsai, H. (2009). On-line Learning Performance and Computer Anxiety Measure for Unemployed Adult Novices Using a Grey Relation Entropy Method. Information Processing and Management. 45 (1), 200-215.

Fei, H., Jinfei, S., Zhisheng, Z., Ruwen, C. ve Songqing, Z. (2014). Canny Edge Detection Enhancement by General Auto-Regression Modeland Bi-Dimensional Maximum Conditional Entropy. Optik. $125,3946-3953$.

Finnet Veri Tabanı (2018). Firma Verisi. https://www.finnet.com.tr/FinnetStore/tr/ (05.04.2018)

Gao, J., Wang, H., You, Z. ve Yang, X. (2018). Gray Relational Entropy Analysis of High Temperature Performance of Bio-Asphalt Binder and its Mixture. International Journal of Pavement Research and Technology. (baskıda makale).

Govindan, K., Rajendran, S., Sarkis, J. ve Murugesan, P. (2015). Multi Criteria Decision Making Approaches for Green Supplier Evaluation and Selection: A Literature Review. Journal of Cleaner Production. 98, 66-83.

Hanbay, K. ve Talu, M. (2014). Segmentation of SAR Images Using Improved Artificial Bee Colony Algorithm and Neutrosophic Set. Applied Soft Computing. 21, 433-443.

Jha, N. K., Kumar, R., Kumari, A. ve Bepari, B. (2014). Design, Development and Implementation of a Robust Decision Support 
Expert System (branDEC) in Multi Criteria Decision Making. Procedia Engineering: 12th Global Congress on Manufacturing and Management. 97, $1853-1865$.

Kumar, N., Singh, A., Verma, A. ve Sonal, T. (2016). Measuring Efficiency of IPL Players Using EATWOS. International Journal of Advanced Production and Industrial Engineering. 1(2), 13-16.

Li, G., Tong, Y. ve Xiao, X. (2011). Adaptive Fuzzy Enhancement Algorithm of Surface Image based on Local Discrimination via Grey Entropy. Procedia Engineering. 15, 1590 - 1594.

Ma, J., Pu, H., Sun, D., Gao, W., Qu, J. ve Ma, K. (2015). Application of ViseNIR Hyperspectral Imaging in classification Between Fresh and Frozen-Thawed Pork Longissimus Dorsi Muscles, İnternational Journal of Refrigeration, 50, 10-18.

Ma, M., Liang, J., Guo, M., Fan, Y. ve Yin, Y. (2011). SAR İmage Segmentation Based on Artificial Bee Colony Algorithm, Applied Soft Computing. 11, 5205-5214.

Özbek, A. (2016). Efficiency Analysis of Gold Mining Companies through Financial Statements, International Journal of Academic Research in Business and Social Sciences, 6 (10), 273-290.

Özbek, A. (2015a). Analysis of Private Pension Companies in Turkey by EATWOS. European Journal of Business and Management. 7 (26), 31-44.

Özbek, A. (2015b). Efficiency Analysis of the Turkish Red Crescent between 2012 and 2014. International Journal of Economics and Finance. 7 (9), 322-334.

Özbek, A. (2017). Çok Kriterli Karar Verme Yöntemleri ve Excel ile Problem Çözümü. Seçkin Yayınclık. Ankara.

Peters, M. L. ve Zelewski, S. (2016). Benefits and Risks of Satisficing Levels for Input And Output Quantities in Efficiency Analyses From A Corporate Social Responsibility Perspective. International Journal of Management and Sustainability. 5 (12), 94-101.

Shuai, J. ve Wu, W. (2011). Evaluating the Influence of E-Marketing on Hotel Performance by DEA and Grey Entropy. Expert Systems with Applications. 38, 8763-8769.

Shuai, J. ve Wu, W. (2011). Evaluating the Influence of E-Marketing on Hotel Performance by DEA and Grey Entropy. Expert Systems with Applications. 38, 8763-8769.

Sivasankar, S ve Jeyapaul, R. (2012). Application of Grey Entropy and Regression Analysis For Modelling and Prediction on Tool Materials Performance During EDM of Hot Pressed Zrb2 At Different Duty Cycles. Procedia Engineering. 38, 3977-3991. 


\section{Aşkın ÖZDAĞoĞLU}

Tseng, M. ve Chiu, A. (2012). Grey-Entropy Analytical Network Process for Green Innovation Practices. Procedia - Social and Behavioral Sciences. 57, $10-21$.

Wang, Y., Sun, L. ve Qin, Y. (2015). Aging Mechanism of SBS Modified Asphalt Based on Chemical Reaction Kinetics. Construction and Building Materials. 91, 47-56.

Wang, Z., Wang, Q. ve Ai, T. (2014). Comparative Study on Effects of Binders and Curing Ages on Properties of Cement Emulsified Asphalt Mixture Using Gray Correlation Entropy Analysis. Construction and Building Materials. 54, 615-622.

You, M., Shu, C., Chen, W., ve Shyu, M. (2017). Analysis of Cardinal Grey Relational Grade and Grey Entropy on Achievement of Air Pollution Reduction by Evaluating Air Quality Trend In Japan. Journal of Cleaner Production. 142, 3883-3889. 